\title{
Least cost combination of renewable generators, storage devices and transmission system in the NEM
}

\author{
Yunyang Wu ${ }^{\text {a b }}$ and Luke Reedman ${ }^{\text {b }}$ \\ ${ }^{a}$ Energy Institute, University College London, London, UK \\ ${ }^{b}$ CSIRO, Newcastle, Australia \\ Email:Luke.Reedman@csiro.au
}

\begin{abstract}
There are differing views on how to achieve a high penetration renewable power system in the Australian National Electricity Market (NEM). The limited hydro resource in Australia makes it more challenging to achieve a $100 \%$ renewable power system than other hydro resource-rich countries, as pumpedhydro plants could act as peaking power plants and provide relatively cheap energy storage. Given the variability and diverse location of wind and solar resources, augmentation of the transmission network and placement of energy storage devices may be key considerations under a high penetration renewable power system.

The model in this paper estimates the least cost combination of renewable technologies, storage devices and transmission infrastructure to meet the projected demand in the NEM in the year 2030. The simulation uses historical data of NEM demand, regional interconnector capacity limits, weather data for wind and solar resources, and monthly hydro plant generation data as a benchmark. Genetic Algorithm (GA) is used as the optimization algorithm to seek the least cost combination of renewable generators, storage devices (existing pumped hydro and new grid-scale batteries) and transmission network upgrades to meet the electricity demand for all NEM regions at hourly temporal resolution.

The results in this paper suggest that the electricity cost of a $100 \%$ renewable power system in the NEM would be ranged from $\$ 100 / \mathrm{MWh}$ to $\$ 163 / \mathrm{MWh}$. Significant flows of power between regions may occur frequently and this will require significant investment in the transmission system. Deployment of battery storage devices along with investment in transmission infrastructure greatly increases the utilization of wind farms and solar power systems.
\end{abstract}

Keywords: Energy modelling, optimization, renewable energy 
Y.Wu and L.Reedman, Least cost combination of renewable generators, storage devices and transmission system in NEM

\section{INTRODUCTION}

There is evidence that greenhouse gas emissions from human activities have accelerated in recent years (IEA, 2014) implying that significant emissions reduction may be required to limit the chances of dangerous climate change. This has significant implications for Australia given its emissions intensive economy (Denis et al., 2014).

Australia's high ranking in emissions per capita reflects its relatively high proportion of fossil fuels in energy consumed, high usage of relatively less efficient private transport and relatively high production of non-ferrous metals per capita (most of which is exported). Stationary energy is the single largest source accounting for around 50 per cent of the total 543 megatonnes $(\mathrm{Mt})$ of carbon dioxide-equivalent $\left(\mathrm{CO}_{2}\right.$-e), with electricity generation accounting for the majority at $179 \mathrm{Mt} \mathrm{CO}_{2}$-e (Commonwealth of Australia, 2014).

The high share of emissions from the stationary energy sector is mainly due to coal-fired electricity generation which accounts for 72.6 per cent of electricity generation in 2013 (ESAA, 2014). The dominance of coal masks Australia's rich diversity of renewable energy resources (wind, solar, geothermal, hydro, wave, tidal, bioenergy). Except for hydro and wind energy which currently account for most renewable generation, these resources are largely undeveloped and could contribute significantly to Australia's future energy supply (Australian Energy Market Operator, 2013; Geoscience Australia and ABARE, 2010).

The transition to a high penetration renewable power system has been widely discussed as a means to reduce greenhouse gas emissions from electricity generation. The literature has identified a number of potential challenges with this type of system. First, such systems usually have high capital costs and levels of installed capacity, particularly if characterized by large amounts of intermittent generation (Budischak et al., 2013). Second, these type of systems may also present operational challenges such as system inertia and frequency control issues in periods of low demand or alternatively reactive power and voltage stability concerns in periods of high demand (Australian Energy Market Operator, 2013). Third, co-optimization of electricity generation and transmission infrastructure may be more important to achieve system balance due to geographic variation in renewable resource availability impacting generation output. Fourth, demand response and storage may be required but are currently nascent in the Australian context.

Most studies about high penetration renewable power systems in Australia focus on whether there is enough renewable energy to meet the demand over a certain simulation period. Some studies discussed the least cost renewable system with different scenarios. However, most of these studies do not include a detailed model of the NEM transmission network when they analyse the renewable system. Accordingly, the importance and the cost of the transmission system in the high penetration renewable system may be underestimated. This paper explores the least cost combination of renewable generators, storage devices and transmission infrastructure in the National Electricity Market (NEM) with a detailed transmission model. Section 2 outlines the model overview, Section 3 discusses optimization results with a focus on the system dispatch in a typical winter week. Section 4 presents sensitivity analysis and Section 5 concludes.

\section{Model overview}

The model used in this paper contains three components: the transmission module, the dispatch module and the optimization module. This section provides detail on each component of the model.

\subsection{Transmission Module}

Table 1 lists the capacity of the existing interconnectors between NEM regions. The length of the interconnectors listed here is not the real physical length. Instead, it is coarsely approximated using the geodetic center of each state and territory obtained from Geoscience Australia.

The capacity rating of interconnectors is determined by the thermal, voltage stability, transient stability and dynamic stability limits of the power system. The Australian Energy Market Operator (AEMO) develops constraint equations which contain several hundred mathematical expressions to calculate the capacity of the interconnectors. We simulate a $100 \%$ renewable power system, which is a significant contrast to the current system dominated by coal-fired generation. The current transmission capacity constraints from voltage stability, transient stability and dynamic stability limits will not be valid in the new system. However, the constraints from thermal limits will still be valid. Hence, the thermal limit of the existing interconnectors is maintained as the input value of the capacity of the interconnectors.

Table 1. Original Interconnectors' Rating

\begin{tabular}{lll}
\hline Interconnectors between regions & Original Capacity (MW) & Approximate Length (km) \\
\hline SA - VIC & 880 & 1100 \\
\hline VIC - TAS & 600 & 600 \\
\hline VIC - NSW & 3200 & 600 \\
\hline NSW - QLD & 1300 & 1100 \\
\hline
\end{tabular}


Y.Wu and L.Reedman, Least cost combination of renewable generators, storage devices and transmission system in NEM

In this module, electricity can be transmitted between two distant, non-adjacent regions. For example, to transmit electricity from South Australian to New South Wales, both SA-VIC and VIC-NSW interconnectors would be used. In this case, the maximum transfer capacity will be determined by the smallest capacity rating of the two interconnectors. Following Dunstall et al. (2013), we assume that the energy loss of the transmission line is $1 \%$ of the electricity transmitted per $100 \mathrm{~km}$. For example, if $100 \mathrm{MW}$ of power is generated in the SA region and transmitted via the Heywood interconnector to VIC, only $89 \mathrm{MW}$ of power will be received in VIC.

This module does not model the transmission and distribution network within each region in order to reduce the complexity of the system. It assumes that there are no constraints on the capacity of the transmission and distribution system within each region.

\subsection{Dispatch module}

\section{Renewable technology set and cost parameters}

Solar photovoltaic (PV) and on-shore wind turbines are chosen as the main renewable generation technologies in this study. These technologies are currently the most cost competitive and mature of renewable technologies. Hourly generation traces of wind and single-axis tracking PV in 2010 in the 43 NEM polygons was used in our model (Australian Energy Market Operator, 2012). The 43 locational polygons are sub-regions of the five NEM regions in order to account for geographical differences in resource quality and quantity. In this paper, we do not model other forms of renewable generation such as geothermal, solar thermal or ocean renewables resource.

Hydroelectricity is the most widely used renewable energy around the world. Although Tasmania and parts of NSW enjoy rich hydro resources, the other NEM regions have very limited hydro capacity. Most studies assume that the expansion of hydro resources is not possible either due to environmental concerns or lack of suitable sites (Elliston et al., 2013). We use the hydro generators data published in the National Transmission Network Development Plan (NTNDP) by AEMO in 2010, shown in Table 2. We applied the data of monthly water inflow and initial storage levels of 2014 in the dispatch model. The model does not consider the evaporation losses but an $80 \%$ round-trip efficiency of the pumped hydro is assumed.

Table 2. Hydroelectricity in NEM regions

\begin{tabular}{lllll}
\hline Region & $\begin{array}{l}\text { Run-of-river } \\
\text { Capacity (MW) }\end{array}$ & $\begin{array}{l}\text { Power } \\
\text { Energy }(\mathrm{GWh})\end{array}$ & $\begin{array}{l}\text { Pumped Hydro Power } \\
\text { Capacity (MW) }\end{array}$ & $\begin{array}{l}\text { Pumped Hydro Storage } \\
\text { Capacity (MWh) }\end{array}$ \\
\hline QLD & 140 & 707 & 500 & 5000 \\
\hline NSW & 3,070 & 5,002 & 840 & 310,000 \\
\hline VIC & 645 & 504 & - & - \\
\hline TAS & 2,170 & 9,098 & - & - \\
\hline Total & 6,025 & 15,313 & 1,500 & 315,000 \\
\hline
\end{tabular}

In addition to existing pumped hydro storage capacity, this study considers the potential role of battery storage in balancing a power system with high penetration of intermittent renewable generation.

Table 3. Technology cost assumptions, 2030

\begin{tabular}{|l|l|l|l|}
\hline Technology & Capital Cost \$/kW & $\begin{array}{l}\text { Fixed O\&M } \\
\$ / \mathrm{kW} / \text { year }\end{array}$ & $\begin{array}{l}\text { Variable O\&M } \\
\$ / \mathrm{kWh}\end{array}$ \\
\hline Wind onshore & $1701-1917$ & 32.5 & 10 \\
\hline PV single Axis tracking & $2013-2542$ & 30 & - \\
\hline Zinc-bromine & $\begin{array}{l}\text { Energy-related cost @ \$260/kWh and Power-related cost @ \$260/kW } \\
\text { O\&M cost @ \$36/kW/year }\end{array}$ & $\$ 800 / \mathrm{MW} / \mathrm{km}$ (Assume that the lifetime for interconnectors is 50 years) \\
\hline Interconnector & (A)
\end{tabular}

The cost of renewable generation technology has decreased significantly in recent years (IRENA, 2015). The model uses renewable technology cost data from Australian Energy Technology Assessment 2013 report (BREE, 2013). The assumed cost of technologies in 2030 is shown in Table 3. The fixed O\&M cost is associated with the capacity of the generators and it includes costs from labour and associated support, fixed service provider, fixed inspection, diagnostic and repair maintenance services etc. The variable O\&M cost is associated with the amount of electricity generated from generators and it includes scheduled and unplanned maintenance.

Similarly, the cost of batteries is expected to decrease in the future as global deployment accelerates (Graham et al., 2013). We consider zinc-bromine flow batteries here for grid-scale application because of its relatively cheaper price. The assumed cost of zinc-bromine battery storage systems is listed in Table 3 .

\section{Regional demand and generation data}

Electricity demand in NEM regions has been declining and is forecast to be lower until 2020. The exception is Queensland where demand is projected to increase mainly due to new liquefied natural gas facilities (Australian Energy Market Operator, 2014). The total annual NEM demand is expected to flatten after 2020. Historical electricity demand data at 30-minute interval for each NEM region in 2010 was used in the dispatch model 
Y.Wu and L.Reedman, Least cost combination of renewable generators, storage devices and transmission system in NEM

(Queensland's demand is scaled with a factor to reflect the increase its electricity consumption based on the AEMO's forecast).

The hourly generation of wind farm and PV is calculated based on the weather condition at the polygon of the generators' site and the capacity of the generators. The generation data is obtained from AEMO 100 per cent renewable study(ROAM, 2012).Monthly water inflow of each hydro station was considered to indicate the availability of its output as noted before.

\section{Dispatch process}

The real-time dispatch algorithm used in the NEM is National Electricity Market Dispatch Engine (NEMDE), which is based on the power demand and the bid price stack of all generating units. The model used in this paper does not simulate the bid stack for each generator since this will greatly increase the computation requirement. We use a simplified dispatch model based on priority dispatch of the nearest available renewable generation.

Generally, local (within region) renewable generation is dispatched first to meet demand. If demand cannot be met by local renewable generation, then renewable generation is imported subject to interconnector capacity, followed by power generated by local or imported run-of-river hydro, pumped hydro and battery storage devices. At the end of each stage, the model checks for surplus or deficit. The deficit regions are balanced via power transfer from surplus regions in the next stage. At the end of the dispatch process, any remaining surplus can charge storage devices subject to constraints on interconnector and storage capacity.

\subsection{Optimization module}

Genetic algorithm (GA) is chosen as the optimization algorithm to seek the least cost combination of renewable generation, interconnector and storage capacity in the system. GA is a part of evolutionary computing and has been widely used as function optimizer in many research fields (Fonseca and Fleming, 1998).

The annualized cost of the system is used here as the evaluation function in GA, and GA trends to find the lowest value during its evolution. The function is given by:

$$
T C=\sum_{t, r} A C C_{t, r}+\sum_{t, r} F O M_{t, r}+\sum_{t, r} V O M_{t, r} * E_{t, r}+\sum_{i c} A C C_{i c}
$$

where "TC", "ACC", "FOM" and "VOM" stands for total cost, annualized capital cost, fixed O\&M cost and variable O\&M cost, respectively. "E" stands for the electricity output by technology by region. The subscripts $t, r$ stand for technology type (except hydro and pumped hydro as expansion opportunities are limited) and NEM region, respectively. The ic stands for the four interconnectors listed in Table 1.

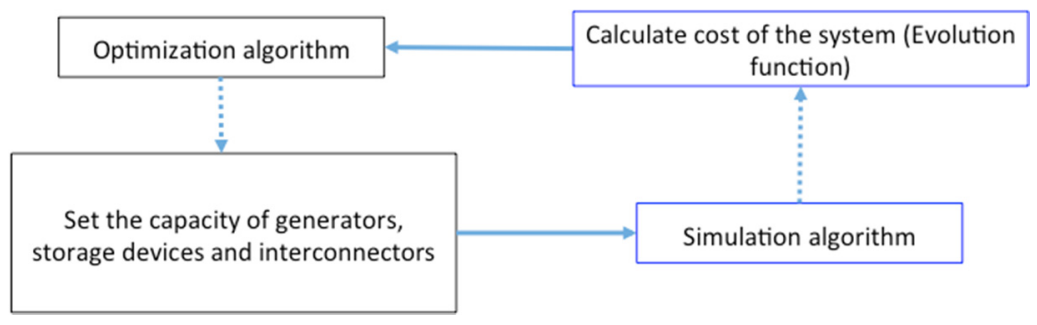

Figure 1. Model flowchart

Figure 1 shows the structure of the optimization module used in the model. The GA sets the optimized capacity mix of the $100 \%$ renewable power system based overall system cost. This mix is then passed to the simulation module. The total annualized cost of generators, batteries and interconnectors is calculated at the end of the dispatch process in the simulation algorithm. Any unserved energy exceeding $0.002 \%$ of the total NEM demand is heavily penalized. After that, the GA uses the cost data from the simulation algorithm to find a better combination of the system and then this new combination will be simulated again.

In order to assist the optimization module in finding the least cost combination quicker, we give a specific capacity range for the renewable generation technologies based on simulation assumption. Based on this assumption, the wind or solar capacity in each state cannot exceed $50 \mathrm{GW}$. The power capacity and energy capacity of the battery devices in each state cannot exceed $8 \mathrm{GW}$ and $30 \mathrm{GWh}$, respectively. The model does not impose a capacity limit of interconnectors.

\section{OPTIMIZATION RESULT}

\subsection{Electricity generation mix}

It is likely that there is only one global minimum cost combination, but many local minima. Like most evolutionary optimization algorithms, finding the global optimum combination of the system is challenging for GA. However, GA is good at finding reasonably acceptable combinations quickly. The optimization results 
Y.Wu and L.Reedman, Least cost combination of renewable generators, storage devices and transmission system in NEM

give several different combinations at a similar cost and we choose one possible least cost combination which has the least shortage hours to discuss the result, shown in Table 4.

Table 4. Possible least cost combination for the NEM, assuming low technology costs with 5\% discount rate

\begin{tabular}{|c|c|c|c|c|c|c|c|}
\hline & & QLD & NSW & $\mathrm{VIC}$ & TAS & SA & Total \\
\hline \multirow[t]{2}{*}{ Wind } & Capacity (GW) & 29.6 & 18.4 & 16.9 & 1.6 & 4.3 & 70.9 \\
\hline & Energy Supplied (TWh) & 36.1 & 39.4 & 33.6 & 3.8 & 6.2 & 119.1 \\
\hline \multirow[t]{2}{*}{ PV } & Capacity (GW) & 11.3 & 10.1 & 4.5 & 1.7 & 4.9 & 32.6 \\
\hline & Energy Supplied (TWh) & 27.0 & 28.0 & 11.6 & 4.0 & 7.6 & 78.2 \\
\hline \multirow[t]{2}{*}{ Run-by-river Hydro } & Capacity (GW) & 0.1 & 3.1 & 0.6 & 2.2 & - & 6.0 \\
\hline & Energy Supplied (TWh) & 0.2 & 7.0 & 1.7 & 4.3 & - & 13.1 \\
\hline \multirow[t]{2}{*}{ Pumped Hydro } & Capacity (GW) & 0.5 & 0.8 & - & - & - & 1.3 \\
\hline & Energy Supplied (TWh) & 0.1 & 0.4 & - & - & - & 0.5 \\
\hline \multirow[t]{3}{*}{ Battery } & Power Capacity (GW) & 3.4 & 3.8 & 2.2 & 4.4 & 3.8 & 17.4 \\
\hline & Energy Capacity (GWh) & 13.0 & 23.9 & 26.1 & 23.9 & 22.4 & 109.3 \\
\hline & Energy Supplied (GWh) & 319.9 & 855.2 & 874.5 & 277.0 & 385.7 & 2712.3 \\
\hline \multicolumn{2}{|c|}{ Total Region Supplied Energy (TWh) } & 63.7 & 75.6 & 47.7 & 12.4 & 14.2 & 213.6 \\
\hline
\end{tabular}

The result shows that wind generators contribute around $56 \%$ of total energy supplied while solar PV contributes around $37 \%$. The total energy supplied by run-of-river hydro is $13.1 \mathrm{TWh}$, which is less than the actual amount (15.39 TWh) of energy supplied by run-of-river hydro in the NEM in 2010. The total power and energy capacity of the batteries in this system is $17.4 \mathrm{GW}$ and $109.3 \mathrm{GWh}$, respectively. The reason for such large capacity requirement can be easily explained that since we do not consider gas turbines or concentrated solar thermal (CST) systems in the model (dispatchable plant), a significant amount of power and energy requirement needs to be met by batteries when insufficient generation is provided by $\mathrm{PV}$ or wind generators in certain regions, such as night-time in winter. This is observed in Figure 3 that most battery storage energy are discharged during the fourth night.

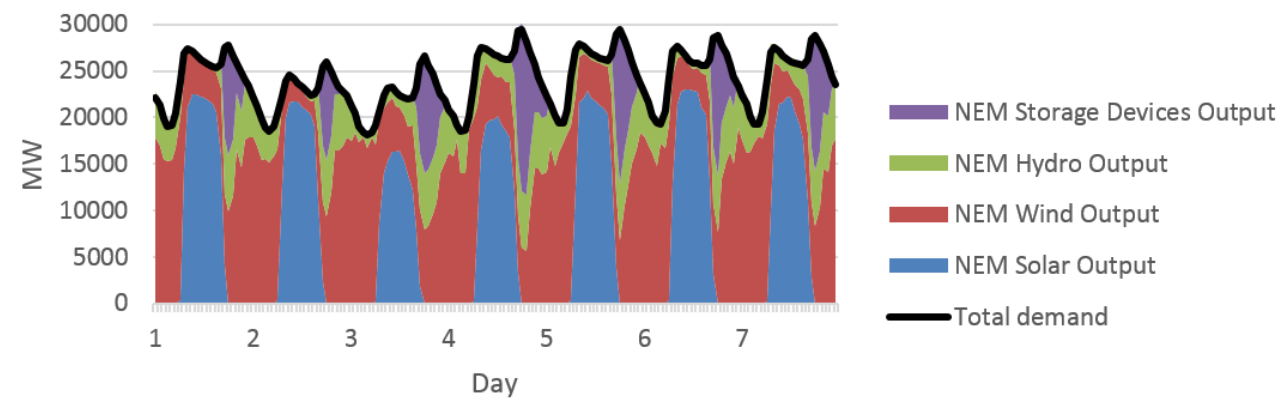

Figure 2. NEM demand and supply in a winter week

Figure 2 shows the supply and demand power during a winter week when most storage energy is used during the year. Spilled energy is not shown in the figure. PV and wind generation are able to meet the demand in most day time periods. Hydro and battery devices are activated during time periods of insufficient renewable generation to meet local demand or demand in other regions. The capacity requirement for batteries in the NEM is $109.3 \mathrm{GWh} / 17 \mathrm{GW}$, which is approximately $19 \%$ of the average daily demands of NEM regions. The hours of discharge for batteries for the five batteries listed in Table 4 are all less than 11 hours. This result is similar as (Solomon et al., 2014) which modelled an $85 \%$ renewable system in California.

The storage level of batteries during the winter week is shown in Figure 3. The batteries usually supply energy during night-time. The batteries provide significant energy in the fourth night. They are quickly charged up by wind energy following the discharge period.

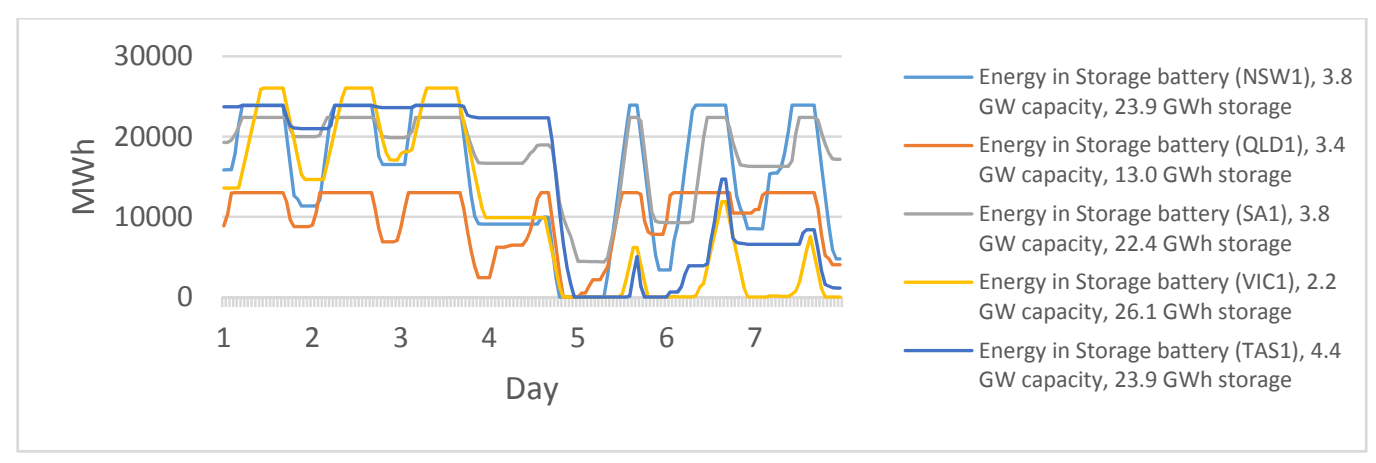

Figure 3. Energy storage level in batteries in the winter week 
Y.Wu and L.Reedman, Least cost combination of renewable generators, storage devices and transmission system in NEM

\subsection{Interconnectors and energy exchange activities}

The need for a large transmission system in high renewable penetration systems is noted in the previous literature (Brand, 2013; Rodriguez et al., 2014). The transmission expansion plan for this least cost combination is shown in Table 5. It shows that the capacity of the interconnectors in NEM regions increase dramatically to support the high renewable energy system, although the overall utilization factors of the interconnectors are less than that of today. For example, the capacity of the VIC-TAS interconnector increases from the current level of $600 \mathrm{MW}$ to $5193 \mathrm{MW}$. This interconnector allows significant export of hydro energy from TAS-VIC.

Table 5: Transmission expansion plan for least cost combination

\begin{tabular}{|c|c|c|c|c|c|c|}
\hline & $\begin{array}{l}\text { Proposed } \\
\text { capacity } \\
\text { by model } \\
\text { (MW) }\end{array}$ & $\begin{array}{l}\text { Total forward } \\
\text { transmitted electricity } \\
\text { in the year }(\mathrm{GWh})\end{array}$ & $\begin{array}{l}\text { Total backward } \\
\text { transmitted electricity in } \\
\text { the year }(\mathrm{GWh})\end{array}$ & $\begin{array}{l}\text { Hours when } \\
\text { flow large } \\
\text { than } 99 \%\end{array}$ & $\begin{array}{l}\text { Hours when } \\
\text { flow large } \\
\text { than } 80 \%\end{array}$ & $\begin{array}{l}\text { Hours when } \\
\text { flow large } \\
\text { than } 50 \%\end{array}$ \\
\hline VIC - TAS & 5193 & 154 & 2057 & 10 & 36 & 127 \\
\hline VIC - NSW & 4835 & 1422 & 4605 & 145 & 348 & 947 \\
\hline NSW -QLD & 8448 & 240 & 6924 & 120 & 242 & 644 \\
\hline
\end{tabular}

Table 6 shows the total energy exported and imported of the five regions during the simulation year. QLD and TAS are major energy export regions reflecting significant renewable capacity in excess of demand, whereas VIC and NSW are major energy import regions reflecting relatively low levels of capacity relative to demand. These outcomes mainly reflect capacity being installed at prime locations (in terms of renewable resource quality) as regional interconnector capacity is unconstrained.

Table 6. Energy Exchange between regions

\begin{tabular}{llllll}
\hline & QLD & NSW & VIC & TAS & SA \\
\hline Import Electricity in GWh & 197.24 & 4175.29 & 5401.67 & 119.10 & 877.19 \\
\hline Export Electricity in GWh & 6925.85 & 1216.75 & 1040.68 & 2058.30 & 1121.40 \\
\hline Net Import(Negative value shows export) & -6728.62 & 2958.54 & 4360.99 & -1939.21 & -244.21 \\
\hline
\end{tabular}

\subsection{Cost analysis}

The total annualized cost of the system is around $\$ 100$ per MWh, assuming low technology costs with $5 \%$ discount rate. The cost would be up to $\$ 163$ per MWh if the high technology costs and $10 \%$ discount rate were used in the model. The following discussion is based on the optimization result assuming low technology costs with $5 \%$ discount rate.

As shown in Table 7, more than half of the total cost comes from wind generation. Solar PV represents $27 \%$ of total cost and storage constitutes $13 \%$. The interconnectors are the smallest contributor, at $3 \%$ of the total cost.

Table 7. System Cost

\begin{tabular}{lllll}
\hline Components & Wind farms & PV & Storage device & Interconnectors \\
\hline Percentage & $57 \%$ & $27 \%$ & $13 \%$ & $3 \%$ \\
\hline
\end{tabular}

The system cost here is much smaller than the cost found in Graham et al. (2013) which used a similar technology set and cost data but projected a wholesale unit cost around \$176/MWh. When optimizing the 100\% renewable system in the CSIRO study, batteries were not dynamically simulated in hourly dispatch and this may underestimate the role and capacity of storage devices (Graham et al., 2013). Another reason for the difference is that the model in this paper assumes that all renewable generation is constructed overnight in 2030 at the prevailing assumed cost. The CSIRO study used an investment model that constructed capacity over the decade prior to 2030 at higher prevailing technology costs.

Table 8. Least cost system in Elliston et al. (2013) and this study

\begin{tabular}{|c|c|c|c|c|c|c|c|c|}
\hline & Technology & Wind & PV & CST & Pumped & Hydro & GTs & Battery \\
\hline \multirow{2}{*}{$\begin{array}{l}\text { Elliston et al. } \\
\text { (2013) }\end{array}$} & Capacity GW & 34.1 & 29.6 & 12.5 & 2.2 & 4.9 & 22.7 & - \\
\hline & Energy TWh & 94.8 & 41.0 & 43.9 & 0.5 & 11.5 & 12.7 & - \\
\hline \multirow[t]{2}{*}{ This study } & Capacity GW & 63.6 & 22.3 & - & 1.3 & 6.0 & - & $16.2 \mathrm{GW}$ with $105.8 \mathrm{GWh}$ storage \\
\hline & Energy TWh & 135.9 & 62.1 & - & 0.4 & 13.4 & - & 1.9 \\
\hline
\end{tabular}

The similar study in Elliston et al. (2013) estimated the cost for a high renewable system at \$104/MWh. The generation mix in this study is compared to that of Elliston et al. (2013) in Table 8. The main contrast is the use of biogas turbines to meet demand in periods of insufficient wind or solar generation. In this study, more wind generation is deployed than solar generation to charge battery storage devices during night-time periods of low demand. 
Y.Wu and L.Reedman, Least cost combination of renewable generators, storage devices and transmission system in NEM

\section{CONCLUSION}

This paper modelled a possible least cost combination of wind and solar generation, battery storage devices and augmentation of regional interconnectors in the NEM for the year 2030. The results showed that battery storage devices have a key role in meeting power demands in a system dominated by intermittent renewable generation. Discharge of battery storage devices is estimated to provide around the $20 \%$ of the average daily demand in NEM regions. The amortized cost of this high penetration renewable power system is around $\$ 100$ per MWh. This cost is similar to other high renewable penetration studies that do not consider batteries as dispatchable plant.

The results show that significant amounts of energy are exchanged between the five NEM regions in such a high renewable energy penetration system. Tasmania and Queensland act as net energy exporters given their relative superior renewable energy resources while New South Wales and Victoria are net energy importers. Significant augmentation of regional interconnectors is required to support this energy exchange, but the overall utilization of this infrastructure is less than that observed in the current system.

The optimization result shown in this paper is dependent on the renewable generation dataset sourced from the AEMO 100\% Renewable project. The high average wind capacity of Queensland in the simulation year causes the optimization to favour placement of more wind farms in Queensland. This may overestimate the wind capacity needed in Queensland (and underestimate wind capacity in other regions) in the simulated high renewable penetration system.

\section{REFERENCES}

Australian Energy Market Operator (2012). 100 percent renewable study - modelling assumptions and input.

Australian Energy Market Operator (2013). 100 per cent renewables study - modelling outcomes. Australian Energy Market Operator, Melbourne.

Australian Energy Market Operator (2014). National electricity forecasting report 2014.

Brand, B. (2013). Transmission topologies for the integration of renewable power into the electricity systems of north africa. Energy Policy 60, 155-166.

BREE (2013). Australian energy technology assessments 2013 (aeta). Bureau of resources and energy economics.

Budischak, C., Sewell, D., Thomson, H., et al. (2013). Cost-minimized combinations of wind power, solar power and electrochemical storage, powering the grid up to $99.9 \%$ of the time. Journal of Power Sources $225,60-74$.

Commonwealth of Australia (2008). Australia's low pollution future: The economics of climate change mitigation, Canberra.

Commonwealth of Australia (2014). Quarterly update of australia's national greenhouse gas inventory: June 2014.

Denis, A., Graham, P., Hatfield-Dodds, S., et al. (2014). Introduction, in: Sue, W., Ferraro, S., Kautto, N., Skarbek, A., Thwaites, J. (Eds.), Pathways to deep decarbonisation in 2050: How australia can prosper in a low carbon world. ClimateWorks Australia, Melbourne, pp. 5-21.

Dunstall, S., ElGindy, T., Jafari, N., et al. (2013). Accounting for renewable energy supply intermittency in energy systems modelling, 20th International Congress on Modelling and Simulation, Adeladie, Australia, pp. $1509-1515$.

Elliston, B., MacGill, I., Diesendorf, M. (2013). Least cost 100\% renewable electricity scenarios in the australian national electricity market. Energy Policy 59, 270-282.

Fonseca, C.M., Fleming, P.J. (1998). Multiobjective optimization and multiple constraint handling with evolutionary algorithms. Ii. Application example. Systems, Man and Cybernetics, Part A: Systems and Humans, IEEE Transactions on 28, 38-47.

Geoscience Australia, ABARE (2010). Australian energy resource assessment, Canberra.

Graham, P., Brinsmead, T., Dunstall, S., et al. (2013). Modelling the future grid forum scenarios. CSIRO. ROAM Consulting.

IEA (2014). World energy outlook. International Energy Agency, Paris.

IRENA (2015). Renewable power generation costs in 2014.

ROAM (2012). Roam report on wind and solar modelling for AEMO 100\% renewables project.

Rodriguez, R.A., Becker, S., Andresen, G.B., et al. (2014). Transmission needs across a fully renewable european power system. Renewable Energy 63, 467-476.

Solomon, A.A., Kammen, D.M., Callaway, D. (2014). The role of large-scale energy storage design and dispatch in the power grid: A study of very high grid penetration of variable renewable resources. Applied Energy 134, 75-89. 